\title{
Mapeamento psicossocial participativo: Metodologia de facilitação comunitária
}

\author{
Psychosocial participatory mapping: Community facilitation methodology
}

Deyseane Maria Araújo Lima[ ${ }^{[a]}$ Zulmira Áurea Cruz Bomfim ${ }^{[b]}$

\footnotetext{
[a] Psicóloga, mestre em Psicologia pela Universidade Federal do Ceará (UFC), especialista em Educação Inclusiva (UECE) e Educação a Distância (Senac), Integrante do Nucepec, Fortaleza, CE - Brasil, e-mail: deyseanelima@yahoo.com.br

${ }^{[b]}$ Doutora em Psicologia Social pela Pontifícia Universidade Católica de São Paulo (PUC-SP), professora do Departamento de Psicologia da Universidade Federal do Ceará (UFC) e do mestrado em Psicologia da mesma Universidade, coordenadora do Laboratório de Psicologia Ambiental (Locus), Fortaleza, CE - Brasil, e-mail: zulaurea@uol.com.br
}

Recebido: $11 / 02 / 2011$ Received: 02/11/2011

Aprovado: 05/04/2011 Approved: 04/05/2011

\section{Resumo}

O artigo a visa a análise da percepção dos jovens sobre a comunidade a partir da metodologia de facilitação comunitária denominada de Mapeamento Psicossocial Participativo com alunos do ProJovem Urbano, com base no referencial teórico da psicologia comunitária. Essa metodologia promove o conhecimento da comunidade, sensibilização com o meio, interação com os moradores e a participação em atividades, bem como o reconhecimento das dificuldades vivenciadas e os potenciais a serem desenvolvidos. A pesquisa desenvolveu-se com natureza qualitativa pautada no método dialógico vivencial. Teve como amostra dez alunos do ProJovem Urbano da Escola Papa João XXIII, no Bairro Vila União, em Fortaleza. Utilizamos a observação participante e a realização do mapeamento psicossocial participativo e de círculos de cultura. Para a análise, recorremos à construção de sentidos. Observamos, portanto, que os jovens participantes tendiam geralmente a se afastar da comunidade, não participando das atividades comunitárias e nem se sentiam pertercentes àquele meio social, necessitando de metodologias participativas para realizar a reinserção social com a comunidade. Concluímos que o mapeamento psicossocial participativo propicia uma reflexão sobre a reinserção e ressocialização dos jovens na sua comunidade, pois consistiu em uma forma de diálogo e de problematização da realidade, por meio do conhecimento e da sensibilização em relação ao contexto social.

Palavras-chave: Comunidade. Reinserção. Sociedade. Subjetividade. Facilitação comunitária.

\section{Abstract}

The article analyzes the perception of young people about the community from the community facilitation methodology named participatory psychosocial mapping with "ProJovem Urbano" program students, based on the theory of community psychology. This methodology promotes community's knowledge, awareness with the environment, interaction with residents and participation in activities, as well as recognition of the difficulties experienced and the potential to be developed. The survey was developed with qualitative nature based on the dialogic experiential method. It had a sample size of ten students from "Escola Papa João XXIII" of the "ProJovem Urbano" program in Vila União, in Fortaleza. We used participant observation and participatory map and the psychosocial and cultural circles. We used the construction of meaning for the analysis. We observed, however, that the participants generally tended to move away from the community, not participating in community activities and not feeling belonging to that social environment, requiring participatory methodologies to accomplish the social reinsertion in the community. We conclude that the 
psychosocial participatory mapping provides a reflection on the reinsertion and reintegration of young people into their communities because it consisted of a form of dialogue and problematization of reality, through knowledge and awareness of the social context.

Keywords: Community. Re-insertion. Society. Subjectivity. Community facilitation.

\section{Introdução}

As metodologias de facilitação na psicologia comunitária podem "... dar ênfase à atuação do profissional no sentido da construção do conhecimento crítico e do cuidado ambiental, tendo como lócus da ação a comunidade em seu dia a dia e em seu potencial de vida comunitária" (Góis, 2008, p. 143).

Possibilitam a troca entre o saber popular e o científico, a autonomia, a compreensão das atividades comunitárias, a transitividade da consciência, o reconhecimento das problemáticas e dos potenciais a serem desenvolvidos.

O mapeamento psicossocial participativo é uma metodologia de facilitação comunitária que tem o objetivo de conhecer a realidade a partir da caminhada, em que proporcionam o reconhecimento da história da comunidade, das atividades, dos significados e dos sentimentos dos moradores em relação ao lugar em que vivem.

Esta pesquisa se constituiu como uma parte da dissertação de mestrado intitulada "ProJovem Urbano da Escola Papa João XXIII do Bairro Vila União: Significados atribuídos pelos jovens na perspectiva da Psicologia Comunitária e da Psicologia Ambiental" e investiga a percepção dos jovens sobre a comunidade a partir do mapeamento psicossocial participativo.

\section{Psicologia comunitária e inserção social}

A psicologia comunitária, na América Latina, iniciou-se pela luta popular, nos movimentos sociais, ressaltando-se o movimento de saúde mental, em que se destaca a mudança da concepção de saúde e a participação da comunidade.

Essa modificação da perspectiva de saúde de curativa para uma ação preventiva e promotora de qualidade de vida ocorreu a partir da luta antimanicomial e a ênfase na comunidade como construtora de sua saúde mental, facilitada pelas relações sociais. 0 processo é denominado por Góis (2005) de saúde mental comunitária.

Assim, é necessário "compreender a saúde mental, como um processo dinâmico que se desenvolve na relação interativa do indivíduo com os aspectos socioambientais, implica na utilização de outra metodologia de intervenção para o sofrimento mental" (Castro \& Cavalcante, 2007, p. 65).

A construção da psicologia comunitária ocorreu a partir da crise da psicologia social tradicional, que estudava: conduta, ajustamento social, atitudes sem relação com a realidade social, que legitimavam o fortalecimento das desigualdades sociais.

A psicologia comunitária, com influência da psicologia social crítica, volta-se para os conhecimentos científicos e os saberes populares e preconiza na práxis o diálogo (Freire, 1983) como forma de tensionar a opressão e a exclusão existentes nas classes populares.

0 diálogo é possível a partir de uma práxis que parta do contexto dos sujeitos comunitários, da reflexão de suas problemáticas, da implicação pelas questões sociais.

Martín-Baró (1996) propõe uma postura política de transformação da realidade social, uma práxis historicizada e contextualizada com a realidade, além da análise do homem e da sociedade. Ao manter essa postura, entendemos que a neutralidade científica é ilusória, pois o psicólogo se implica criticamente na comunidade.

Diante disto, há a construção na América Latina de uma psicologia social crítica comprometida com as questões sociais no seu contexto histórico-cultural (Ximenes, Nepomucemo \& Moreira, 2008).

Para Ximenes, Nepomucemo e Moreira (2008, p. 65), "a psicologia comunitária e as teorias apresentadas possuem conceitos e concepções que visam à libertação do homem e da sociedade em que ele está inserido". Tal libertação ressalta o compromisso do psicólogo na luta contra as desigualdades sociais e manutenção do sistema por meio da desnaturalização da realidade. Então, demonstra a relevância do 
tripé: teoria, prática e compromisso social. A psicologia comunitária, para Góis (2008, p. 82),

... se orienta por uma práxis libertadora, a partir das próprias condições (atuais e potenciais) de desenvolvimento da comunidade e de seus moradores. 0 fundamental é a compreensão do modo de vida da comunidade e a realização de seus potenciais de desenvolvimento pessoal e social.

Neste sentido, essa psicologia preocupa-se com a realidade local, a articulação entre morador-comunidade-municipalidade, com a participação social, as mudanças sociopolíticas, a co-construção de sujeitos comunitários, a vivência e a análise da atividade comunitária, o desenvolvimento comunitário dentre outros.

A atividade comunitária é considerada um processo interativo (Leontiev, 1978; Vygotsky, 2004), dialógico e cooperativo (Freire, 1983) realizado pelos moradores como sujeitos comunitários, em prol da satisfação das necessidades e o desenvolvimento comunitário. Relaciona-se com as ações condizentes com o modo de vida dos moradores, propiciando mudanças pessoais e sociais (Góis, 2005).

Além de visar ao diálogo sobre as problemáticas da comunidade, proporciona uma ação transformadora na realidade. É "orientada por ela mesma e pelo significado (sentido coletivo) e sentido (significado pessoal) que a própria atividade e a vida comunitária têm para os moradores da comunidade" (Góis, 2005, p. 89).

Por sua vez, a consciência relaciona-se ao mundo de forma dialética, histórica, social e crítica a partir da atividade. Neste sentido, observamos que a atividade e a consciência estão vinculadas, pois se baseia na ação e no diálogo dos sujeitos, que possibilita o processo de conscientização.

... compreendemos a consciência como a propriedade da mente que dá sentido, tanto à vida psíquica, como à própria atividade externa dos indivíduos, e que esta atividade, por sua vez, orienta e dá a substância da própria consciência. Portanto, esta é formada, sob determinadas condições da atividade prática social e da própria mente ... (Góis, 2005, p. 318).

A conscientização é um processo dialético de historicização, um método de aprendizagem: o homem exerce e efetiva a sua liberdade, luta para "ser mais", insere no seu contexto histórico e busca sua afirmação no mundo com os outros. Possibilita o anúncio das insatisfações pela situação de opressão e exclusão social (Freire, 1983).

Esta concepção é similar a psicologia comunitária, pois, ao partir da atividade desenvolvida pelos moradores da comunidade, é possível promover a transitividade da consciência em relação ao seu modo de vida, à cooperação e à participação social.

Ao assumir a conscientização como horizonte do quefazer psicológico, reconhece-se a necessária centralização da psicologia no âmbito do pessoal, mas não como terreno oposto ou alheio ao social, mas como seu correlato dialético e, portanto, incompreensível sem a sua referência constitutiva. Não há pessoa sem família, aprendizagem sem cultura, loucura sem ordem social; portanto, não pode tampouco haver um eu sem um nós, um saber sem um sistema simbólico, uma desordem que não se remeta a normas morais e a uma normalidade social (Martín-Baró, 1996, p. 17).

A comunidade, para Góis (2005), é um espaço físico, social e ambiental em que seus moradores estabelecem laços afetivos e um sentimento de pertencimento. Estes vivenciam dificuldades, necessidades, problemas e representações sociais semelhantes, num território que é compartilhado e delimitado geograficamente.

Propicia interações sociais entre os moradores, a realização de atividades e a reivindicação dos direitos. Para os jovens, é um espaço fora do meio familiar de desenvolvimento pessoal e coletivo. A partir de atividades comunitárias, os jovens conhecem o modo de vida local e estabelecem o vínculo com o lugar e moradores.

O aprofundamento da consciência dos moradores em relação ao seu modo de vida deflagra o desenvolvimento do sujeito comunitário e da comunidade.

O que distingue o sujeito da comunidade do indivíduo dependente, rebelde ou submisso que ali vive, é que o primeiro tem uma consciência transitiva que lhe permite compreender o modo de vida de sua comunidade e de si mesma, além de reconhecer seu valor e poder para desenvolvê-la e desenvolver-se numa perspectiva dialógica e solidária ... (Góis, 2005, p. 53).

Os sujeitos comunitários são protagonistas do contexto em que estão inseridos, são atores de construção do processo, à medida que se percebem como transformadores da sua realidade, promovendo o 
crescimento pessoal e social. É corresponsável pela realidade histórico-social em que vive (participante) e possui potencial para desenvolvê-la e transformá-la à medida em que se transforma, como sujeito da realidade (Góis, 2008).

Ao realizarmos uma facilitação com a comunidade, é fundamental a inserção social do psicólogo comunitário. Segundo Montero (2006), ao entrar em contato com ela o profissional como agente externo conhece a realidade e realiza seu trabalho. 0 profissional é reconhecido pela comunidade, isso promove a sensibilização e o estabelecimento da confiança e do respeito mútuo.

Quando o psicólogo insere-se na comunidade gera curiosidade, questionamentos e estranhamento pelos moradores, pois o profissional é inicialmente alheio à realidade.

Com base nisto, Freitas (1998) afirma que a relação deve acontecer dos dois lados, o psicólogo tem seus conhecimentos científicos, seus estudos, sua práxis; e a comunidade tem sua dinâmica que é inerente, complexidade, valores e concepções.

O mútuo reconhecimento propicia a relação horizontal e a relevância do saber popular e científico. Góis (2005, p. 66), ressalta a postura do psicólogo comunitário:

O importante, a nosso ver, é que haja uma integração e relação pedagógica entre agente externo e comunidade, na qual se reconheça o papel e a importância de cada interlocutor na definição do rumo e do modo de desenvolvimento apropriados à realidade sócio ambiental do lugar. 0 sentido do desenvolvimento e o controle da ação devem ser da comunidade ... ou, pelo menos, definidos e compartilhados de comum acordo. Isso implica um desenvolvimento participativo, autossustentável, de busca de autonomia local, de interdependência, e não de dependência ao exterior da comunidade.

Montero (2006) considera que o processo de familiarização é contínuo, que ocorre do início até o término das facilitações, pois sempre estamos nos familiarizando com a comunidade e conhecendo-a; assim, como a comunidade em relação aos profissionais.

É imprescindível a inserção do psicólogo no modo de vida para desvelar a realidade, apropriar e levantar as necessidades e possibilidades com a comunidade (Ximenes, Nepomucemo \& Moreira, 2008).

Promove relações solidárias e éticas entre o profissional e a comunidade, demonstrando a práxis do psicólogo comunitário.
Freitas (1998) nos alerta sobre o desafio e as incertezas do processo de inserção, pois há um momento de aceitação, de entrada e de permanência na comunidade. É essencial saber como atuar, como superar as dificuldades e minimizar os preconceitos.

El lengaje esterotipado, o formal y cauteloso, los rodeos y, peor aún, las expresiones inadecuadas, usadas por desconocimiento de la cultura y de los modos específicos de una comunidad, son productos de la ausencia de familirización y tienen consecuencias que dificultan lo que introducen desviaciones en el trabajo psicológico comunitario (Montero, 2006, p. 83).

A aceitação do profissional no âmbito comunitário possibilita a realização do seu trabalho e promove reflexões sobre a comunidade. Esta pode identificar os problemas, buscar ações para resolver as dificuldades e promover mudanças sociais significativas.

Freitas (1998) cita instrumentos utilizados na inserção com a comunidade, como entrevistas (individuais ou coletivas), registros em diários de campo, pesquisa documental, recuperação da história do lugar, conversas informais (bares, calçada, mercados, padarias...), caminhadas pela rua, participação em reuniões comunitárias, visitas a casa, a festa ou a um evento da comunidade.

Na psicologia comunitária, a presença de metodologias participativas potencializa a atuação do profissional da área por meio de instrumentos construídos de acordo com a necessidade do local e dos fatores políticos, históricos, pessoais e ambientais. Neste estudo, enfocamos uma das metodologias de facilitação comunitária, o mapeamento psicossocial participativo, que facilita a compreensão dos saberes e assuntos da comunidade e as influências nos processos sociais.

\section{Mapeamento psicossocial participativo}

O que seriam mapas, o mapear? 0 que significa o mapeamento?

"Mapear é representar a realidade de modo a organizar as informações que tornem possível o reconhecimento e a orientação de quem venha a utilizar este instrumento, o mapa, que é uma das mais antigas formas de comunicação ..." (Oliveira \& Diogo, 2002, p. 190).

Neste sentido, ao realizar o mapeamento no contexto comunitário, tenta-se utilizar um instrumento 
que traga o máximo possível de elementos relacionados ao lugar, suas pessoas, como vivenciam, como é seu modo de vida.

É psicossocial por envolver aspectos subjetivos e sociais. Isto não acontece de maneira dicotômica, mas percebendo os aspectos na sua totalidade, como, por exemplo, a afetividade, as desigualdades sociais e a exclusão. Rodrigues $(2007$, p. 13) afirma que o "mapeamento ... deve enfatizar a dimensão sociopsicológica do lugar e não apenas quantitativa, demográfica e econômica".

Neste sentido, acrescentamos a perspectiva da participação, pois o mapeamento deve ser realizado cooperativamente com ênfase no social, psicológico e ambiental. Para Bordenave (2002, p. 16) a participação "é uma necessidade fundamental do ser humano", que se refere a uma intervenção na construção da sociedade, na interação com os outros, na expressão de sentimentos e o desenvolvimento pessoal e social.

A participação não deve ser atribuída apenas a fazer parte do consumo, dos bens materiais, mas reivindicar os seus direitos, o desenvolvimento das políticas públicas, constitui e transforma o homem e a sociedade (Bodernave, 2002). Em resumo, a participação não é algo em que o estado autoriza a sociedade, não é a recepção passiva dos direitos e, portanto, não deve ter uma óptica assistencialista nem compensatória.

É relevante a presença de espaços públicos permeados pelos interesses individuais e coletivos; e pelos trabalhos conjuntos e cooperativos, que são presenciados na participação comunitária (Góis, 2005). É uma luta pela cidadania dos atores locais, sujeitos de direitos e da sua história e não apenas usuários do serviço público.

A participação comunitária remete a manifestação e mobilização dos moradores da comunidade a partir da realidade, compreendendo-a como integrante da sociedade.

É possível, para Bodernave (2002), que a participação, no âmbito comunitário, promova o engajamento dos seus moradores na sociedade como cidadãos participativos.

Esta breve discussão sobre a participação nos faz refletir sobre o a papel do psicólogo na inserção da comunidade, pois é fundamental que a comunidade se responsabilize, aproprie-se do processo e possa construir com o profissional.

Efetuamos, na pesquisa, o mapeamento psicossocial participativo, que se refere ao levantamento de dados pelo psicólogo no contexto comunitário de forma cooperativa e dialógica. É a vivência da comunidade, conhecimento das atividades comunitárias, percepção dos significados, os sentidos e os sentimentos dos moradores em relação ao lugar em que vivem. Isso ocorre a partir da caminhada pela comunidade e por conversas com os moradores e os líderes comunitários. 0 mapeamento, ao ser realizado com a comunidade, conforme Góis (2008), promove a análise dos aspectos sociais, psicológicos e ambientais da comunidade, tanto pelo psicólogo comunitário quanto pela comunidade, facilitando a interação entre estes.

0 processo de mapeamento se divide em dois: o mapeamento interno e o externo. 0 mapeamento interno consiste na investigação e organização dos dados fornecidos pela documentação de segmentos fundamentais da administração municipal, a saber, as Secretarias de Infraestrutura, Educação, Cultura e Desporto e Saúde e Ação Social. Esta ação resulta [grifo nosso] numa maior valorização da sistematização do conhecimento que estes setores possuem sobre o município (Oliveira \& Diogo, 2002, p. 190).

Sobre o mapeamento interno, Montero (2006, p. 79) complementa que

Antes de entrar a una comunidad es necessario informarse de la manera más completa posible sobre ella. Si existen registros públicos en los cuales se puedan obtener datos demográficos, ellos deben ser consultados, al igual que su historia a través de crônicas y noticias de prensa. Otros datos de interés también puden encontrarse em los archivos de instituiciones públicas que hayan tenido que ver con la comunidad objeto de estudio.

Já, o mapeamento externo, segundo Oliveira e Diogo (2002, p. 190), "é realizado através de visitas às localidades, onde se procura conhecer a realidade local através dos moradores". Além disto, é possível reconhecer as atividades de produção e de lazer, os estilos de vida, os hábitos, os potenciais e os problemas do cotidiano pelos moradores que convivem em uma comunidade.

Destacamos, então, que o mapeamento não é só uma visita à comunidade na busca de seus equipamentos, monumentos, estruturas e as organizações sociais. Mas, sim, uma forma de apreensão da realidade, a forma como os moradores estão inseridos, como pensam, sentem e vivenciam. Pode-se 
observar a maneira como os moradores vinculam-se ao lugar e às pessoas, o fortalecimento dos laços afetivos, dentre outros.

Para a comunidade, é o reconhecimento de seu próprio contexto e de efetivação de mudanças a partir de momentos de definição conjunta entre profissional e moradores, pois o objetivo não seria a transmissão de informações, nem a palestra, mas a problematização da realidade, sua reconstrução a partir do diálogo e ação coletiva.

Então, ressaltamos, que, para Montero (2006), não é interessante que as pessoas digam só o que o pesquisador/profissional quer escutar, pois apresenta as aparências e referem-se às expectativas dos moradores em relação a estes.

É essencial que os moradores possam verbalizar o que realmente acontece na sua comunidade. E o psicólogo possa entrar em contato por meio da caminhada comunitária e por conversas com os moradores e os líderes comunitários. Essas visitas devem ser orientadas por pessoas que morem no lugar, para torná-las proveitosas e agregar informações, além de possibilitar parcerias.

Segundo Góis (2008), "andar pela comunidade é muito mais do que simplesmente passar pelos lugares, é olhar para cada ponto, cada lugar, cada morador, cada situação que se apresenta no local de andança, com um olhar sensível e perceptivo ...."

Portanto é uma metodologia participativa que promove a inserção e a reinserção com a comunidade. 0 mapeamento inclui levantamento de dados de ordem documental (dados já escritos sobre a comunidade), caminhada comunitária e problematização da comunidade pelos moradores. Para Castro (2009, p. 38),

Falar em convivência significa um compromisso e envolvimento ético e amoroso do psicólogo comunitário com a comunidade com a qual trabalha. Não se pode falar em atuação comunitária sem que esta seja precedida de inserção, ou seja, de um mergulho profundo no modo de vida da comunidade, suas histórias, angústias, cultura, significados, equipamentos sociais, relações, lideranças, entre muitos outros aspectos que a realização do mapeamento psicossocial participativo permite compreender e vivenciar.

A comunidade é um espaço mediado pela sociedade, os laços familiares, o município, a sociedade e as relações interpessoais, que permite a construção da identidade dos seus moradores e reconhecimento de si, do outro e do contexto.
A mediação é presente no estudo de Sánchez Vidal (1991) sobre a comunidade, em que é caracterizada pela interação entre os moradores e a sociedade, é a expressão das instituições sociais que a compõe, podendo satisfazer as necessidades mútuas.

\section{Procedimentos metodológicos}

A pesquisa foi de natureza qualitativa, com base no método dialógico vivencial (MDV), cuja análise do material coletado foi feito com base na construção de sentidos (Moreira, 2004).

Foram investigados dez alunos da Escola Papa João XXIII do ProJovem Urbano, com idade entre 18 a 29 anos. 0 lócus do estudo foi a comunidade Vila União, situada nas proximidades da Avenida Borges de Melo, na Regional IV, em Fortaleza.

Apresenta dificuldades referentes ao saneamento básico, à segurança pública e à existência de um canal na região. Os moradores são envolvidos em lutas sociais e participação comunitária, propiciando reivindicações à prefeitura.

0 pesquisador, ao vivenciar a comunidade, deverá introduzir-se nas relações cotidianas e conhecer o modo de vida comunitário. Essa compreensão enfatiza-se na dinâmica e no impacto psicossocial na comunidade.

A partir da necessidade desse processo de transformação sujeito-comunidade, a psicologia comunitária utiliza o método dialógico-vivencial (Góis, 2008) para conhecer e aprofundar a leitura dessa realidade concreta da comunidade. Como o nome indica, esse método tem como premissas básicas a vivência da comunidade e o diálogo com seus atores, seus grupos e suas instituições. ... Vivenciar o modo de vida comunitário significa compartilhar junto a pessoas da comunidade sentimentos, sentidos, significados que surgem a partir do seu dia a dia naquele lugar ... (Ximenes, Amaral, Rebouças \& Barros, 2008, p. 92).

Permite, assim, a transformação da realidade, demonstra a práxis do psicólogo comunitário e a interação com a comunidade. Possibilita deflagrar processos nos moradores referentes ao lugar, uma releitura da realidade e ações transformadoras a partir do facilitar-pesquisando.

Utiliza-se o método facilitar-pesquisando (Góis, 2008), que envolve facilitação e pesquisa em um processo contínuo de construção de conhecimento, 
interação socioambiental e desenvolvimento pessoal e coletivo dos profissionais e da comunidade.

$\mathrm{Na}$ pesquisa, realizamos a observação participante e os círculos de cultura com os jovens do programa na sala de aula. Inicialmente explicamos os objetivos e desenvolvimento da pesquisa e os estudantes interessados assinaram o termo de consentimento. Depois, fizemos atividades pautadas na discussão das questões ambientais vivenciadas na comunidade, efetuando um momento de sensibilização para as trilhas urbanas pautado na relação que têm com o ambiente e o compromisso com o contexto. No segundo dia, realizamos uma trilha na escola e, após a sua efetuação, facilitamos um círculo de cultura sobre o que pensaram e sentiram naquele momento, além de relacionar com o ProJovem Urbano. Passamos uma atividade de casa sobre a comunidade Vila União, em que deveriam fazer uma pesquisa sobre o bairro. No terceiro dia, falaram sobre a história da comunidade a partir das matérias sobre o Vila União. No quarto dia, para finalizar, fizemos uma trilha pela comunidade e efetuamos um círculo de cultura para que pudessem verbalizar sobre o que perceberam no encontro.

0 círculo de cultura, por meio do diálogo problematizador, deflagra a vivência dos jovens em relação às metodologias por meio de trocas simbólicas e do processo grupal, gerando questionamentos e reflexões, além da construção de novos sentidos, conhecimentos e leituras da realidade. Segundo Góis (2008, p. 188),

O círculo de cultura faz parte do eixo metodológico que parte de uma educação como prática de libertação. Círculo quer dizer a forma como as pessoas estão sentadas fazendo a palavra 'circular' por entre todas, estando cada uma em pé de igualdade para falar e ouvir atentamente. Cultura, por que todos ali têm um conhecimento e uma experiência de vida, fazem parte daquele lugar; pensam, agem, criam e têm algo a dizer para os outros, contribuindo para o conhecimento coletivo e transformação da realidade.

Neste estudo, realizamos as trilhas guiadas. Seria relevante perceber a trilha com os jovens, promovendo a apreensão da realidade pelo público-alvo, permitindo a interação entre o grupo e o pesquisador.

$\mathrm{Na}$ coleta de dados utilizamos a gravação e a transcrição dos diálogos para assegurar o registro preciso. Não utilizamos fotografias, pois os jovens não aceitaram.
O diário de campo foi usado durante o estudo, que consiste, para Montero (2006), em descrições do que aconteceu no campo, suas observações, dúvidas, questionamentos, acertos, a superação e aprendizagem com seus erros.

\section{Percepções dos jovens sobre a comunidade}

0 mapeamento psicossocial participativo é uma forma de conhecer a comunidade sob a perspectiva dos seus moradores. Assim, o psicólogo insere-se no contexto, familiariza-se, conhece as necessidades e percebe os potenciais. À medida que a comunidade conhece o profissional, conhece seus objetivos e interage, gerando uma confiança mútua entre os sujeitos (Montero, 2006).

Permite a visão ampla da realidade, pois concebe os aspectos demográficos, sociais, culturais, econômicos, históricos e afetivos, buscando os conhecimentos objetivos e s subjetivos da comunidade.

0 mapeamento psicossocial participativo compreende a pesquisa documental, o levantamento de dados, a reflexão sobre a comunidade e a caminhada comunitária. Não seria somente conhecer a comunidade sem perceber a realidade dos seus moradores, o seu modo de vida comunitário e a sua subjetividade. Diante disto, podemos conhecer a comunidade da Vila União sob a óptica dos estudantes do ProJovem Urbano e observar a percepção sobre a metodologia de facilitação, como no caso do aluno: "a comunidade Vila União é calma e tranquila, temos praças, hospital de criança que é o Albert Sabin" (aluno 1, 26 anos, estudante).

A partir da discussão e da problematização da comunidade, percebemos aspectos relevantes da realidade, pois o aluno comenta que onde mora é tranquilo. Há opiniões diferenciadas sobre a segurança, pois alguns participantes do grupo acreditam que é um bairro perigoso, já que presenciaram fatos de violência, assaltos em suas casas, ou na vizinhança. Esse diálogo possibilita uma reflexão e acolhimento do comentário do colega, respeitando o seu posicionamento, propiciando novas significações sobre o lugar. Assim, segundo a estudante: "não acho que o Vila União seja um bairro calmo" (aluna 2, 20 anos, estudante).

Comparam a sua comunidade com outros lugares, para que, a partir disto, consigam perceber o lugar onde moram pacificamente, afirmando que 
podem andar pela rua, pedir informação, sem que ocorra violência. Refletem os estereótipos que são apresentados na televisão e nos jornais sobre a outra comunidade. Então, uma jovem comenta que: "o Lagamaré muito mais violento e perigoso" (aluna 4, 24 anos, estudante).

Retratam as dificuldades na comunidade e demonstram uma postura individualista, sem se preocupar com o contexto comunitário e o grupo social, como é relatado pela estudante: "problema no Vila União tem, mas ninguém pode resolver o problema de todo mundo. Cada um tenta resolver o seu problema, a sua dificuldade ..." (aluna 4, 24 anos, estudante).

Essa reflexão sobre a comunidade faz parte do mapeamento psicossocial participativo, pois consiste em levantamento de dados sobre o contexto e um reconhecimento da realidade comunitária sob a óptica dos seus moradores, além de observar a percepção que apresentam em relação ao lugar e a sua transformação.

A comunidade é um lugar de aprendizado e socialização entre os moradores. Possui a dimensão física, o território, o lugar, que a retrata geograficamente, além de um viés sociopsicológico, uma interação das pessoas com o lugar (Góis, 2005).

Vila União é um lugar bom de morar, há uma apropriação dos moradores em relação ao lugar, bem como o sentimento de pertença e a afetividade em relação às pessoas e à comunidade, como podemos perceber no comentário: "acho que é um lugar que tudo que nós queremos nós conseguimos, é um lugar que tudo é perto" (aluna 6, 18 anos, estudante).

No item sobre a saúde na comunidade Vila União, como comenta a aluna: "percebi que a praça é muito bem localizada, mas se envolvem com coisas estranhas, como drogas, não fazem sexo com camisinha, aí pode pegar alguma doença, alguma coisa ruim ..." (aluna 6, 18 anos, estudante).

Diante disto, percebemos que os jovens, geralmente, não se protegem contra as doenças e a gravidez de forma consciente e que usam drogas. No decorrer da vida do jovem, os comportamentos de risco podem incluir a atividade sexual arriscada, o uso de álcool, a violência, o abandono da escola, a pouca interação social e o desemprego.

Em relação à saúde, sobre os hospitais do bairro, o aluno comenta a sua percepção: "o hospital é maior do que imaginava" (aluno 10, 27 anos, estudante).

Tem o colégio dos ricos da região bem perto, dava pra ver direito. Sonho em colocar meus filhos lá, até liguei uma vez, mas foi complicado, sabia. É muito caro, né e ainda tem o material, o lanche, que é por minha conta (aluna 6, 18 anos, estudante).

Na perspectiva da educação, os jovens percebem as diferenças sociais e verbalizam os seus sonhos para os seus filhos. Em referência à religião, notamos que a maior parte é católica, mas há pessoas evangélicas e que praticam religiões africanas, como é relatado: "a maioria é católica, né, mas tem muita gente evangélica. Há preconceito com as pessoas evangélicas aqui, o povo não gosta muito, mas é claro que tem gente que é muito exagerado ..." (aluno 1, 26 anos, estudante).

O lugar que chama atenção dos jovens é a praça. É o lugar mais frequentado, pois encontram os colegas, namoram e dançam. Associa-se ao passeio e à diversão com os grupos sociais, pois na juventude há construção de novos interesses além da família, como afirma: "nós desenhamos a praça, que é um lugar que nós frequentamos bastante, é bem animado todos os dia" (aluno 1, 26 anos, estudante).

Apreendemos a relevância atribuída aos serviços, aos equipamentos sociais e aos transportes, como, por exemplo, os colégios, os postos de saúde, o hospital, as praças, além de compreender a questão da saúde, da religião, da educação, do lazer e esporte.

Conhecemos a localização da Vila União, ou seja, onde começa e termina o bairro sob a perspectiva dos jovens. Além disto, retrataram a história do bairro.

Começa lá na Borges de Melo, passa pela escola, e termina lá na lagoa perto do aeroporto velho, onde tem a praça do boi (que não lembro o nome certo, mas todo mundo aqui chama desse modo), tem uma delegacia (aluno 1, 26 anos, estudante).

A atividade propiciou o interesse para procurar os dados, que finalizou com a atividade de casa, que seria procurar matérias sobre o bairro, tais como a percepção do lugar que moram, presentificando-se um sentimento de comunidade, de pertencimento àquele contexto social, pois seria a realidade maior, que reflete a comunidade em que vivem, mostrando valores e condições sociais, presente no trecho do diálogo a seguir: "Achei massa este texto, por que relembro as histórias do meu avô sobre a nossa comunidade. Apesar de não em lembrar direito" (aluna 6). "Não conhecia esta história. Que legal! Massa! ..." (aluna 2). 
Assim, os jovens leram o que pesquisaram em casa sobre a comunidade, conheceram um pouco da história do seu bairro, surgindo momentos de surpresa, lembranças das histórias dos avôs, entre outros. Assim, a aluna comenta: "eu vi esta matéria na televisão, é muito bom ter o nosso bairro valorizado e divulgado para a cidade" (aluna 6, 18 anos, estudante).

Neste sentido, jovens reconheceram e sentiram valorizados em relação ao seu bairro, quando foi apresentado na televisão na cidade. Concordaram com o material coletado, pois havia identificação com o conteúdo proposto e mostraram lugares que já comentaram e relataram a história do bairro, que até esta pesquisa não conheciam bem.

Compreendemos que o mapeamento psicossocial participativo não se resume somente à caminhada comunitária, mas ao material e ao conteúdo já produzido sobre o local. É importante realizar a pesquisa documental, como por exemplo, buscar relatórios, documentos, matérias de jornais, escritos da comunidade, que devem ser lidos pela comunidade e pelos profissionais, gerando um posicionamento crítico.

Além de discutir, levantar os dados e pesquisar em documentos é relevante a caminhada comunitária, pois possibilita vivenciar a realidade pelos moradores e pelo psicólogo, propiciando um conhecimento do contexto social em sua práxis. A partir da caminhada, discutimos sobre os lugares a partir de um elemento diferencial: a vivência. Demonstravam então a sensibilidade, a afetividade e a mudança da percepção.

Andar pela comunidade é muito mais do que simplesmente passar pelos lugares, é olhar para cada ponto, cada lugar, cada morador, cada situação que se apresenta no local de andança, com olhar sensível e perceptivo. Um olhar que une o etnográfico ao psicológico, um olhar etnopsicológico alicerçado no compromisso social, um olhar amigo que busca compreender a comunidade do ponto de vista científico, vivencial e solidário (Góis, 2008, p. 197).

Podemos experienciar o cotidiano dos moradores, os lugares que gostam de ir, os idosos na calçada, os casais namorando, constituindo-se a convivência comunitária.

A caminhada comunitária é um andar realizado em grupo, no qual se juntam para caminhar pelas ruas da comunidade profissionais de saúde e moradores, com o fim de conhecer os locais, as pessoas, as situações, ouvir estórias, saber da história do lugar, dar-se a conhecer e estabelecer laços de convivência, estar mais dentro e por dentro do cotidiano do lugar. A caminhada comunitária quer dizer um andar coletivo, visando a olhar junto, compreender junto e atuar junto (Góis, 2008, p. 197).

Quando caminham juntos, fica mais fácil a interação entre os jovens ou outros participantes, que se surpreendem com o lugar, com as pessoas que estão presentes, podem perguntar, conversar com os outros moradores e trocar impressões. É na comunidade que ocorre a formação de grupos, o estabelecimento de vínculos, a expressão de sentimentos e a convivência. Assim, de acordo com Castro (2009, p. 38),

Falar em convivência significa um compromisso e envolvimento ético e amoroso do psicólogo comunitário com a comunidade com a qual trabalha. Não se pode falar em atuação comunitária sem que esta seja precedida de inserção, ou seja, de um mergulho profundo no modo de vida da comunidade, suas histórias, angústias, cultura, significados, equipamentos sociais, relações, lideranças, entre muitos outros aspectos que a realização do mapeamento psicossocial participativo permite compreender e vivenciar.

Portanto, enfatizamos a participação dos jovens na caminhada comunitária, bem como na tomada de decisões e a responsabilidade pelo processo.

A tomada de atitude que me refiro representa a participação na construção e melhoria do seu lugar de vida. Entendo que esta só acontece, de fato, quando existem sentimentos de implicação entre os indivíduos e destes com seu lugar. A participação comunitária fornece a base para o fenômeno do aprofundamento da consciência (Rodrigues, 2007, p. 62-63).

Além disto, notamos as pessoas que frequentam o lugar, a identificação com as casas, as diferenças entre um lugar do bairro e de outro, o movimento e o silêncio nas ruas, ou a opção por não observar, sendo consciente ou não. Sentiram diferença das ruas perto da escola, em comparação ao lugar onde vivem e habitam.

Quando realizavam caminhadas no ProJovem Urbano com os professores, estes não caminhavam, pegavam seus carros e chegavam no ponto marcado.

Foi boa a caminhada, vocês foram com a gente, é diferente das que acontecem no ProJovem, que vamos 
caminhando e os professores vão de carro, eles não acompanham a gente, podemos ir brincando, conversando, tem gente que vai embora depois da presença e pronto. Isto desmotiva os alunos, sabe. Vocês foram com a gente, conversando com a gente, perguntando algumas coisas... (aluno 1, 26 anos, estudante).

Acreditamos que a postura de distanciamento do professor/educador pode deixar os jovens dispersos, podem ir para a casa (sem participar da atividade) e não permite a vinculação, a troca de informações, a construção do processo, dentre outros.

Em relação aos estudantes do ProJovem Urbano, já conhecem a comunidade, mas geralmente não há interação com os seus moradores e a realização de atividades comunitárias. Os relatos dos estudantes confirmam que são essenciais atividades que permitam a sua aproximação, a reinserção, a vinculação dos jovens com a comunidade.

Quando caminhamos é que realmente conhecemos o lugar, quando ando de ônibus pelos cantos é tão rápido que não dá para notar nada, né. Mas, caminhando é diferente, você passa por cada lugar e ele fica marcado em você de alguma forma. Eu já havia passado diversas vezes por esta praça, desta foi diferente, consegui passar com calma e perceber a importância para a nossa comunidade e sua boa localização, num precisa andar muito para ir ao médico, comprar alguma coisa, ir ao colégio... (aluno 1, 26 anos, estudante).

Para o mapeamento psicossocial participativo, é importante que a caminhada aconteça em vários momentos (fins de semana e na semana) e horários (manhã, tarde e noite), para compreender o cotidiano da comunidade e os modos de experienciar cada momento. À noite, a realidade pode se apresentar de forma diversificada, com a presença de elementos para mudar a percepção sobre o lugar (Góis, 2008).

Nesta pesquisa, realizamos uma caminhada comunitária com os jovens à noite. É necessário para o processo de mapeamento que ocorra encontros com a comunidade, com duração de quatro a seis meses, ou mais tempo de acordo com a necessidade, como preconiza o aluno: "eu gostei porque a caminhada fez com que a conversa toda chegasse na nossa discussão sobre o ProJovem daqui mesmo, nem sei como isto aconteceu, né. Foi assim que foi..." (aluno 10, 27 anos, estudante).

Ao realizarmos o diálogo sobre a comunidade, o levantamento de dados, a pesquisa documental e a caminhada, percebemos que os jovens comentaram sobre o ProJovem Urbano. Foi um instrumento que permitiu a verbalização sobre o programa, sendo um campo fértil para a facilitação e a realização de pesquisas na área da psicologia, da educação e da saúde.

Sobre a participação no grupo, os jovens comentaram que propiciou o desvelamento da realidade: "... caminhamos, conhecemos mais a nossa comunidade, o nosso bairro, e também pudemos falar algumas coisas que estavam engasgados sobre o ProJovem" (aluno 1, 26 anos, estudante). Assim, observamos que a pesquisa, com o uso do mapeamento psicossocial participativo, promoveu a aproximação dos jovens à realidade, iniciando o processo de pertencimento, sensibilização e interesse em referência à comunidade.

\section{Considerações finais}

A realização do mapeamento psicossocial participativo foi importante tanto para o pesquisador quanto para os jovens, pois possibilitou refletir e sentir a comunidade. Promoveu o reconhecimento da comunidade e as possibilidades de transformação, fortalecendo o trabalho comunitário e desvinculando as situações de opressão. Propiciou a identificação e pertencimento ao grupo, bem como o resgate das redes sociais e o exercício da cidadania, pela diminuição dos preconceitos e a superação dos sentimentos de rejeição, de insegurança, de vergonha e de culpa.

Tem um viés de facilitação comunitária, de pesquisa, de inserção e reinserção com a comunidade, de conhecimento e reconhecimento dos participantes. É possível trabalhar várias temáticas com a comunidade a partir de suas demandas.

Para a psicologia comunitária, essa metodologia possibilita o conhecimento de equipamentos sociais, que poderia efetivar uma parceria de trabalho, buscando, entre outros processos, a potencialização das atividades comunitárias presentes, a discussão das problemáticas encontradas e a busca de soluções. Assim, diante da realidade vivenciada, reconhecemos os objetivos em comuns com os parceiros e a comunidade, que levem ao desenvolvimento comunitário e atuação comprometida.

Tanto para o profissional de saúde como para o morador que participa da caminhada comunitária, esta gera um pertencer e um sentido maior da vida da comunidade, um conhecimento impossível de se 
obter ficando dentro de um posto de saúde, de casa, ou andando pelo lugar sem prestar devida e profunda atenção, só possível numa postura vivencial e etnográfica de interesse genuíno, compromisso social e solidariedade (Góis, 2008, p. 198).

\section{Referências}

Bordenave, J. E. D. (2002). 0 que é participação. São Paulo: Brasiliense.

Castro, G. S. de. (2009). Diálogos e vivências sobre arte e identidade com jovens do Bom Jardim. Dissertação de Mestrado não publicada, Programa de Pós-Graduação em Psicologia, Universidade Federal do Ceará, Fortaleza.

Castro, G. S. de, \& Cavalcante, J. A. M. (2007). Psicologia comunitária e produção do espaço urbano nos diálogos sobre saúde mental comunitária. In A. C. F. Cordeiro, E. M. Vieira \& V. M. Ximenes (Org.). Psicologia e(m) transformação social: Práticas e diálogos (pp. 57-70). Fortaleza: Aquarela.

Freire, P. (1983). Pedagogia do oprimido. Rio de Janeiro: Paz e Terra.

Freitas, M. de F. Q. (1998). Inserção na comunidade e análise de necessidades: Reflexões sobre a prática do psicólogo. Psicologia Reflexão e Crítica, 11(1), 175-189. doi:10.1590/S0102-79721998000100011

Góis, C. W. L. (2005). Atividade e consciência. Fortaleza: Instituto Paulo Freire.

Góis, C. W. L. (2008). Saúde comunitária: Pensar e fazer. São Paulo: Aderaldo \& Rothschild.

Leontiev, A. (1978). 0 desenvolvimento do psiquismo. Lisboa: Horizonte Universitário.

Martín-Baró, I. (1996). O papel do psicólogo. Estudos de Psicologia, 2(1), 7-27.
Montero, M. (2006). Hacer para Transformar: El método en la psicologia comunitária. Buenos Aires: Paidós.

Moreira, D. A. (2004). 0 método fenomenológico na pesquisa. São Paulo: Thomsom Pioneira.

Oliveira, F. P. de, \& Diogo, N. M. F. (2002). Programa Conversando com a cidade uma instância de diálogo e participação comunitária na administração municipal de Maracanaú. In P. R. Lustosa, A. A. Pinheiro \& V. M. Ximenes (Org.). Práxis em Psicologia: Contribuições do NUCEPEC, do PET e do NUCOM (pp. 185-194). Fortaleza: UFC.

Rodrigues, D. S. (2007). Conscientização: Um estudo sobre os sentidos e sentimentos envolvidos nesse processo. Monografia da Universidade Federal do Ceará não publicada, Programa de Graduação em Psicologia, Universidade Federal do Ceará, Fortaleza.

Sánchez Vidal, A. (1991). Psicología Comunitária: Bases Conceptuales y operativas métodos de intervención. Barcelona: Ppu.

Vygotsky, L. (1984). A formação social da mente. São Paulo: M. Fontes.

Ximenes, V. M., Nepomucemo, B. B., \& Moreira, A. E. M. M. (2008). Cooperação universitária: Um caminho dialógico, libertador e crítico construído no Núcleo de Psicologia Comunitária. In V. M. Ximenes, C. E. Menezes \& F. G. Rebouças Jr. (Org.). Psicologia comunitária e educação popular: Vivências de extensão cooperação universitária no Ceará (pp. 63-88). Fortaleza: LC Gráfica.

Ximenes, V. M., Amaral, C. E. M., Rebouças, F. G. Jr., \& Barros, J. P. P. (2008). Desenvolvimento local e desenvolvimento comunitário: Uma visão da Psicologia Comunitária. In V. M. Ximenes, C. E. Menezes \& F. G. Rebouças Jr. (Org.). Psicologia comunitária e educação popular: Vivências de extensão cooperação universitária no Ceará (pp. 89-104). Fortaleza: LC Gráfica. 